\title{
Effect of olive core and olive core ash on the growth of Helianthus annuus and soil quality
}

\author{
Kalavrouziotis I.K. ${ }^{1}$, Soultanopoulos A. ${ }^{2}$ and Varnavas S.P. ${ }^{3, *}$ \\ ${ }^{1}$ School of Science and Technology, Hellenic Open University, Tsamadou 13-15 \& Saint Andreas, Patras GR-26222, Greece \\ ${ }^{2}$ Markou Botsari 7, Atalanti, 35200, Fthiotidas, Greece \\ ${ }^{3}$ Department of Geology, University of Patras, Patras GR-26504, Greece \\ Received: 02/05/2017, Accepted: 25/08/2017, Available online: 22/09/2017 \\ *to whom all correspondence should be addressed: \\ e-mail: s.p.varnavas@upatras.gr
}

\begin{abstract}
Field experiments were carried out using Helianthus annuus in an attempt to improve the quality of soil conditions by application of industrial waste. A range of quantities of olive core, olive core ash and a mixture of the two kinds of waste were applied. In all experimental fields the plants reached their maximum height on the $80^{\text {th }}$ day of their growth. The application of olive core increased the plant height and decreased the soil $\mathrm{pH}$, suggesting an increase in the nutrient element bioavailability. There was also evidence that olive core increased the soil microbe biomass. Furthermore, olive core woodash gave the dry biomass of Helianthus annuus a boost.
\end{abstract}

Keywords: Olive core, Growth, Helianthus Annuus, Soil Quality

\section{Introduction}

The interval of biological cycle of Helianthus depends on genotype and the climatic conditions prevailing during the growing season (Olivier and Annandate, 1998; Ferreira and Abreu, 2001). Compared to lower temperatures that elongate the biological cycle, at high temperatures plants use more water and sunshine producing greater biomass (Cirilo and Andrade, 1994, Andrade, 1995). Younger plants usually exhibit greater resistance at low temperatures rather than older ones. The photosynthetic capability of the plant reaches its maximum at $28{ }^{\circ} \mathrm{C}$. The maximum production in seed is achieved at temperatures ranging between 24 and $26{ }^{\circ} \mathrm{C}$ during the day and 18 and $20{ }^{\circ} \mathrm{C}$ during the night.

Helianthus can grow in a variety of latitudes from Russia to Argentina and can be cultivated in a variety of soil types from sandy to clayey even in soils poor in nutrients. It can also grow in slightly acid to neutral soils. The maximum leaf surface is controlled by the density of the plants in the field. The period of life of the leaves is also an important parameter (Xanthopoulos, 1993). Leaf surface, being of the most important parameters for Helianthus that controls its productivity and reflects its capability in using the water and the nutrients (Unger, 1981; 1983), was one of the parameters used in the investigations carried out in this study.

The rate of increase of Helianthus root, being greater than that of the above soil plant part, is very characteristic. As the plant reaches a height of $40 \mathrm{~cm}$ its root has a length of $70 \mathrm{~cm}$. At the first stage of the plant development a considerable number of secondary roots develop horizontally until they use all surface water. Then secondary roots tend to increase vertically downwards. The maximum root length can reach $150-270 \mathrm{~cm}$.

Regarding the plant density population of the Helianthus crop, recent experiments showed that optimum production is accomplishable at 4500-5000 plants/ha for non-irrigation corpus and 5500- 6000 plants/ha for irrigation corpus. It is noted that the nutrient concentration levels in the irrigation waters as well as in the soils play an important role in the biomass production (Kalavrouziotis et al. 2002; 2006; 2007).

\section{Materials and methods}

An experiment was conducted in the region of Atalanti, Greece (38 3924.44 N, 230201.32 A.E.) at an altitude of $32 \mathrm{~m}$ using a completely randomized block design, with the application of the following treatments: (i) Control, (ii) olive core waste, (iii) Olive core ash, and (iv) Olive core ash + olive core waste. Helianthus annuus $L$ was used as the experimental crop. Sowing date was April 25, 2011. The dimensions of the experimental plots were $2 \times 3 \mathrm{~m}$, that is $6 \mathrm{~m}^{2}$ plot surface. Soil was prepared through mixing and homogenizing the waste at $20 \mathrm{~cm}$ depth. On the basis of the physical characteristics, the experimental soil is described (according to Bouyoucos, 1962 classification system) as sandy silt soil $(49.3 \%$ sandy, $28.7 \%$ clay, $22 \%$ loam) with a calcium rich substrate, $\mathrm{pH}$ of 8.1 and organic content of $1.45 \%$ (Mitsios, 1999).

The olive core was mixed with soil in various proportions to make the following four treatments: the witness that was $100 \%$ soil (M-treatment); the E-treatment included olive core $7 \%$; the T-treatment comprised olive core ash $1.5 \%$; and the ET-treatment was a mixture of olive core $8 \%$ and 
olive core ash $1.5 \%$. The experimental layout in regards with the type of waste used in each plot is described in Figure 1. Plant height, dry weight biomass and the surface of the leaf of Helianthus were examined, so as to ascertain the effects of olive core waste on plant growth.

Olive Core: Olive core is a solid waste derived from olive oil industries after the separation the oil. The water content of the soil waste varies between $38 \%$ and $65 \%$ depending on the method used, the type of olives and the time of the activity. The remaining of the solid waste consists of $45 \%$ wooden material, oil 3-4\%, as well as organic and inorganic constituents being responsible for the smell. Greece is the third olive oil production country in the world following Spain and Italy with an annual production of olive core wood varying between 700,000 and 800,000 tones. Considering an annual production of olive core wood of 5000,000 tones the annual production of ash in Greece is 42,000 tones.

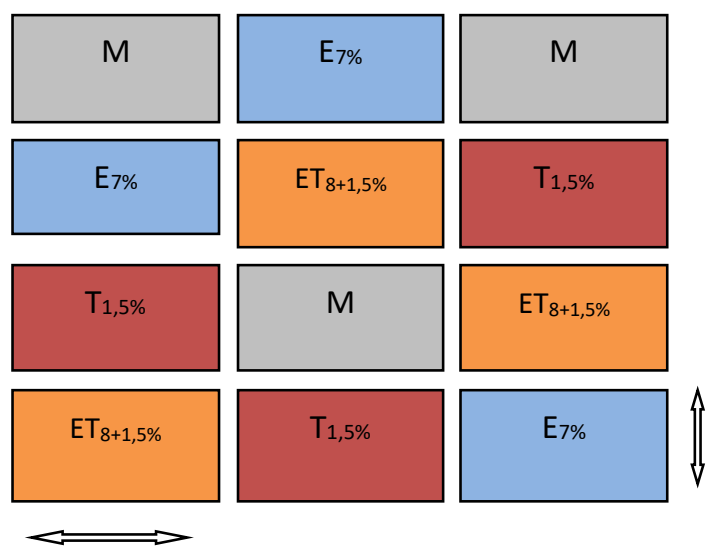

Figure 1. Description of the experimental plot arrangements (Where: M: Reference planting, E 7\%: Olive core $7 \%$ of the soil in the upper $20 \mathrm{~cm}$, T 1, $5 \%$ : Olive core ash 1, $5 \%$ in the upper $20 \mathrm{~cm}$ of the soil, ET $8 \%+1,5 \%$ :

Olive core $8 \%$ with olive core ash $1.5 \%$ ).

\section{Results and Discussion}

\subsection{Determination of the Physicochemical characteristics of the waste}

The physicochemical characteristics of the waste and methods of analysis used are shown in Table 1.

It can be seen that $\mathrm{pH}$, Electrical conductivity, $\mathrm{C} / \mathrm{N}$ ratio, total carbon and especially sodium content of the olive core ash, differ significantly from the corresponding values of the wet olive core. Obviously the ashing of the core at $250{ }^{\circ} \mathrm{C}$ resulted in the concentration of the salts, and of course in the decrease of carbon and organic matter.

\subsection{Leaf area determination}

Leaf surface determination measurements were carried out on the $5^{\text {th }}-6^{\text {th }}$ and $16^{\text {th }}-17^{\text {th }}$ leaves. For the leaf surface measurement leaf length and width were measured using the software Auto CAD 2010.

A copy of the leaf on a paper was made followed by scanning (AREA AUTOCAD). Five plants from each experimental field were sampled and their biomass was determined after drying at $100{ }^{\circ} \mathrm{C}$. The surface measurement of the $16^{\text {th }}$ leaf, showed a decrease in its surface under the olive core, and olive core ash, application. In both cases the decrease level of leaf surface was similar compared to the control, in agreement with other researchers who also found that the application of olive core reduces the plant height and the leaf surface (Alt and Kromhout, 1997; Bouranis et al., 1995). These researchers refer to compost olive core though. Fig. 2 shows the variability of leaf area in relation to time variability during the plant growth at various applications of waste in the present experiment.

Table 1. Chemical and physical characteristics of the wet olive core and olive core ash used in the experiment

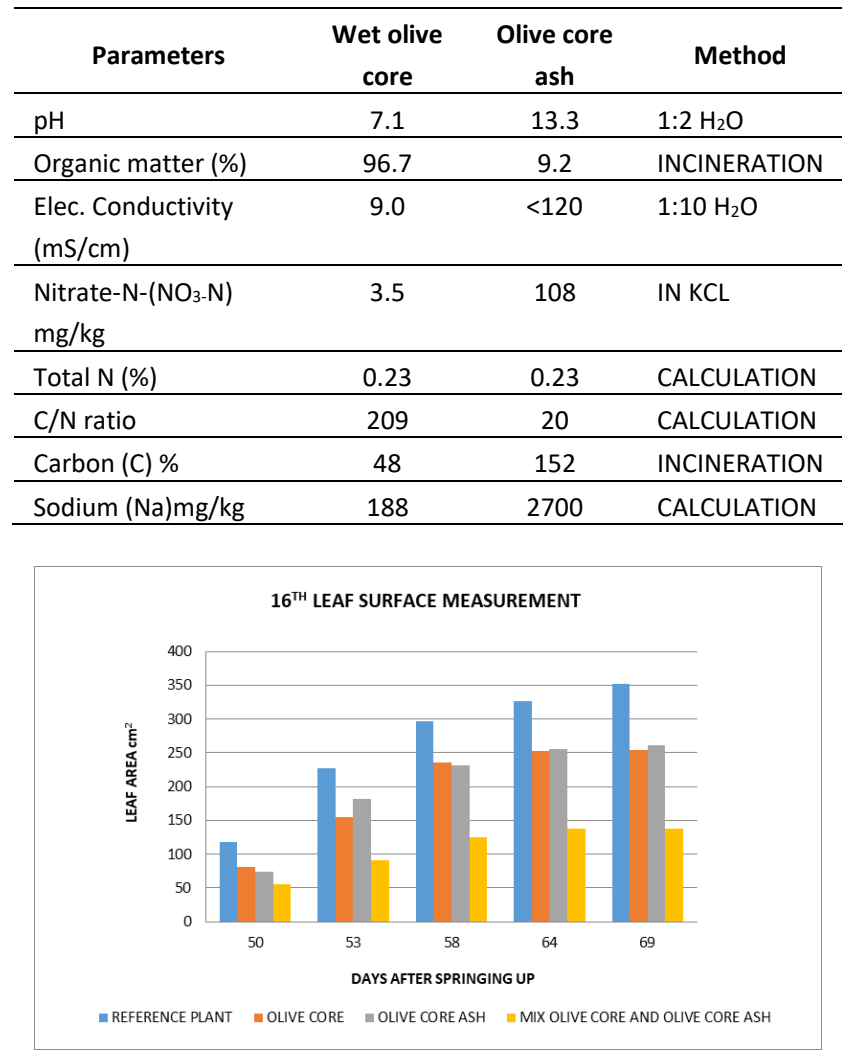

Figure 2. Variability of leaf area in relation to time variability during the plant growth at various applications of waste

\subsection{Height measurements}

During the plant growth period the following measurements were made:

- Measurements of height every 10 days between soil surface and plant top. At flowering the height was measured every two days between soil surface and top of the flowers.

The results of plant height measurements under the effect of experimental treatments are shown in Fig. 3.

At the $35^{\text {th }}$ day of growth there were no statistically significant differences between the height values among the various experimental treatments. Similarly, no statistically significant height differences were observed at the $53^{\text {th }}$ day of growth in any of the experimental 
treatments. The plants under the effect of all treatments reached their highest height on the $80^{\text {th }}$ day of growth, while after this day their height remained constant. After the $80^{\text {th }}$ day and onward there was a positive influence of the olive core on the increase of plant height differing statistically significantly from the reference plants (control).

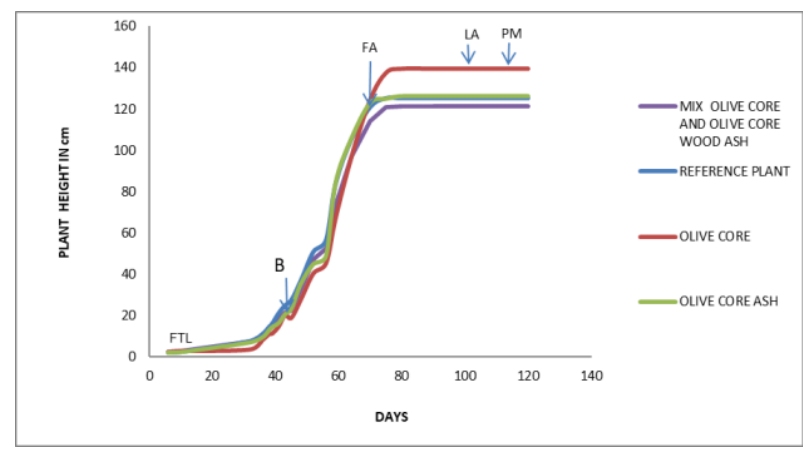

Figure 3. Increase of plant height during the growth period from first true leaf to physiologic maturity ( $F T L=$ First true leaves, $B E=B$ ud Emergence, $B E=B u d$ Emergence, $\mathrm{LA}=$ Last anthesis, $\mathrm{LA}=$ Last anthesis, $\mathrm{PM}=$ Physioloic maturity)

Consequently, it can be concluded that the olive core constituents have a positive influence on the growth of the plants. Foliar surface and plant height were reduced at higher concentrations of total olive core. This agrees with the observations of other researchers (Alt and Kromhout, 1997; Bouranis et al., 1995). Similar results were observed on tomato plants. This most probably is due to the improvement of the soil quality achieved by the olive core on soil structure and fertility. This may be the result of favorable effect of olive core on certain soil parameters such as increase of the availability of nutrient element, and improvement of the substrate favoring the microbial activity that leads to increase of microbial biomass.

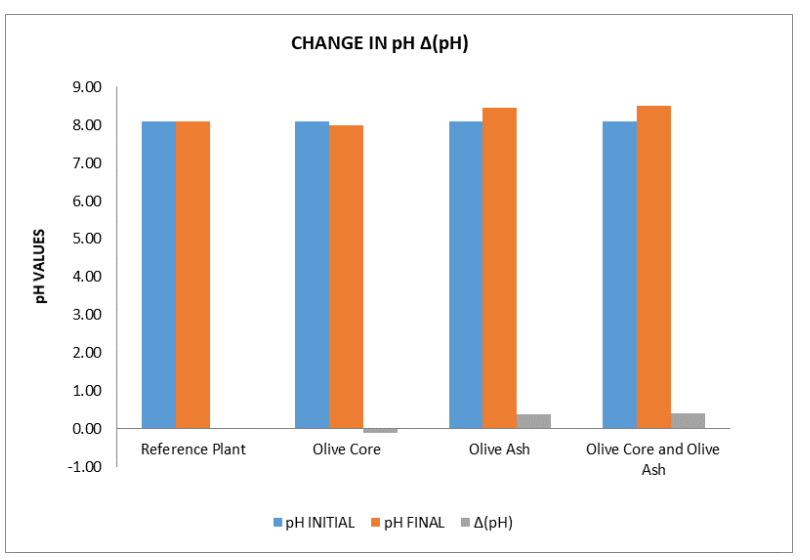

Figure 4. Effect of the applied treatments on soil $\mathrm{pH}$

Another important positive influence of the application of olive core on soil was the decline in the initial $\mathrm{pH}$ value, i.e. 7.99 versus 8.10 (Fig.4).

It is therefore suggested that $\mathrm{pH}$ decrease leads to the increase of the elemental bioavailability, a factor playing an important role in the development of the plants.
By contrast, the application of the olive core ash led to an increase of the soil $\mathrm{pH}$ value from 8.10 to 8.47 (Fig. 4). The surface measurement of the $5^{\text {th }}$ leaf showed a decrease under the olive core, relative to the control. A decrease in the leaf surface but smaller than that described above was also observed for the plants under the olive core ash application (Fig. 2). The height, being a characteristic parameter, was strongly influenced by the climatic and soil conditions and played an important role in seed and oil production (Frangella et al., 2002). The surface measurement of the 16th leaf, showed a similar decrease in its surface under the olive core, and olive core ash, application. In both cases the decrease compared to the leaf surface of the reference (control) treatment (with no applications) was similar.

Ferreira and Abreu (2001), studied the dry biomass of Helianthus in relation to its biological cycle and concluded that it reaches its maximum weight at the stage of blooming. Afterwards, the corpus and leaf biomass decreases. In the present experiment, the measurement of the dry weight was carried out 94 days after the seeding. Also, the seed moisture was measured and was found to be $17 \%$.

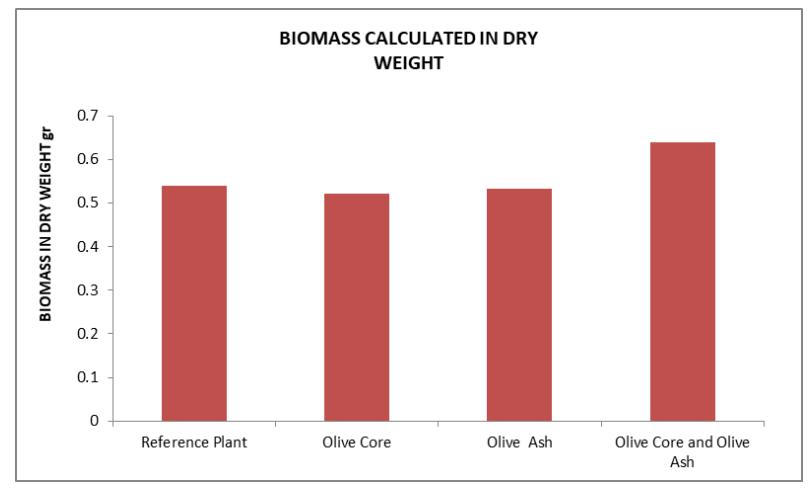

Figure 5. Effect of the applied treatments on dry weight of biomass

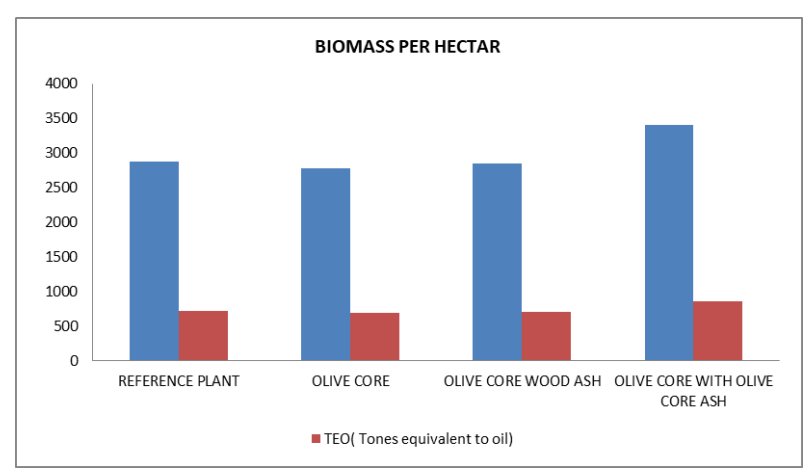

Figure 6. Dry biomass per ha in relation to TEO (tones equivalent to oil, 1 tone biomass equals to 0.4 tone oil)

The analysis of the above diagrams (Figs 4, 5 and 6) showed that the cultivation of Helianthus in the present experiment produced 3- 3.5 tons of dry biomass/ha.

The application of the olive core ash in the present experiment showed an increase in the dry biomass production. 


\section{Conclusions}

1. Cultivation experiments of Helianthus annuus showed that industrial waste can be applied on the field during crop growth improving the quality of soil conditions. Because of the high proportion of $\mathrm{C} / \mathrm{N}$ it could be used as soil enhancer without further process.

2. Olive core and olive core ash treatments showed that the plants in plots reached their maximum height on the $80^{\text {th }}$ day of their growth.

3. The application of olive core resulted in an increase of the maximum height of the plant relative to the reference plant.

4. Availability of nutrient elements in the olive core waste and / or its action as microorganism substrate may justify its positive role in the growth of Helianthus annuus. The presence of olive core waste in the soil may increase the microbe biomass, increasing the fertility of the soil.

5. The application of olive core decreased soil $\mathrm{pH}$ by 0.11; in turn it is expected to increase the bioavailability of nutrient elements.

6. In contrast, olive core wood ash in the soil increased $\mathrm{pH}$ by 0.37 .

7. Dry biomass measurements showed an increase in the dry biomass of Helianthus annuus after the application of olive core ash in the soil.

\section{References}

Alt D., and B. Kromhout (1997),'Einfluss von mull Kompost - torf mischungenauf das wachstum von tomaten und salatjugplanzen, Landwirtsch 'Forsch., 30, pp. 130 - 136

Andrade F.H. (1995), Analysis of growth and yield of maize, sunflower and soybean grown at Balcarce, Argentina, Field Crops Res., 41, 1-12.

Bouranis D.L., Vlyssides A.G., Drossopoulos J.B. and Karvouni G. (1995), Some characteristics of a new organic soil conditioner from the co-composting of olive oil processing wastewater and solid residue, Commun. Soil Sci. Plant Anal., 26, $2461-2472$.

Cirilo A.G. and Andrade F.H. (1994), Sowing date and maize productivity. II. Kernel number determination, Crop Sci., 34, 1044-1046.

Ferreira A.M. and Abreu F.G. (2001), Description of development, light interception and growth of sunflower at two sowing dates and two densities, Mathematics and Computers in Simulation J., 56, 369-384.

Fragella Z., Rottuno T., Tarantino E., Di Caterina R. and De Caro A. (2002), Changes in seed yield and oil fatty composition of high oleic sunflower (Helianthus annuus L.) hybrids in relation to the sowing date and water regime, Eur. J. Agron., 17, 221-230.

Kalavrouziotis I.K. and Drakatos P.A. (2002), Irrigation of certain Mediterranean plants with heavy metals, International Journal of Environment and Pollution, 18(3), 294-300.

Kalavrouziotis I.K., Carter J., Varnavas S.P., Mehra A. and Drakatos P.A. (2006), Towards an understanding of metal contamination in food crops and soils related to road traffic, Fresenius Environmental Bulletin, 15(3), 170-175.

Kalavrouziotis I.K., Carter J., Varnavas S.P., Mehra A. and Drakatos P.A. (2007), Towards an understanding of the effect of road pollution on adjacent food crops: Zea mays as an example,
International Journal of Environment and Pollution, 30(3-4), 576-592.

Mitsios J. (1999), 'Soil Science', Zymel Athen.

Olivier F.C. and Annandate J.G. (1998), Thermal time requirements for the development of green pea, Field Crops Res., 56, 301-307.

Unger P.W. (1983), Irrigation effects on sunflower growth development and water use, Field Crops Res., 3, 181-194.

Unger P.W. (1981), Time and frequency of irrigation effects of sunflower production and water use, Soil Sci. Soc. Am. J., 46, 1072-1076.

Xanthopoulos F.P. (1993). Helianthus. National Foundation of Research. Thessaloniki, 112. 